\title{
Product Lifecycle Management Maturity Models in Industry 4.0
}

\author{
Kássio Cabral Pereira dos Santos ${ }^{\mathrm{a}, \mathrm{b}}$, Eduardo de Freitas Rocha Loures ${ }^{\mathrm{a}}$, \\ Osíris Canciglieri Junior ${ }^{\text {a }}$, Eduardo Alves Portela Santos ${ }^{\text {a }}$ \\ ${ }^{\text {a }}$ Pontifical Catholic University of Paraná, Curitiba, Brazil \\ ${ }^{\mathrm{b}}$ Positivo University, Curitiba, Brazil \\ \{kassio.santosepucpr.edu.br\} \\ $\{$ kassio.santos@up.edu.br\}
}

\begin{abstract}
Today's manufacturers face ever-increasing demands of variability, greater customization of the products, smaller lot sizes, sudden supply-chain changes, and disruptions. With intelligent factories and products, changes will happen in the way the products will be manufactured, impacting on various market sectors. PLM holds the promise of seamlessly integrating and making available all of the information produced throughout all phases of a product's life cycle to everyone in an organization, along with the key suppliers. Industry 4.0 will make it possible to gather and analyze data across machines, enabling faster, more flexible, and more efficient processes to produce higher-quality goods at reduced costs. A research question then arises: What are the opportunities found between the Product Lifecycle Management Maturity Models and the Industry 4.0? Thus, this research proposes a literature review to identify the main researches related to Product Lifecycle Management Maturity Models, adopting the Knowledge Development Process Construtivist (ProKnow-C) method. For that, the AHP method was conducted to verify the adherence of the PLM maturity models having as reference the Industry 4.0 criterias (RAMI 4.0 and perspectives), allowing a diagnostic view about the existing maturity models. As a result, future research opportunities concerning PLM maturity models through Industry 4.0 perspectives are highlighted.
\end{abstract}

Keywords. Industry 4.0, Product Lifecycle Management, Maturity Models, Multicriteria Decision Making/Analysis.

\section{Introduction}

The world is amidst a revolution in the way products and services are created and delivered, comparable in effect to mechanization, mass production, and automation. The agents of that shift are new technologies in data capture, transmission, storage, and processing. The development towards the fourth industrial revolution has presently a substantial influence on the manufacturing industry. It is based on the establish- 
ment of smart factories, smart products and smart services embedded in internet of things. The main principles of Industry 4.0 have been firstly published by [1] and have built the foundation for the Industry 4.0 manifesto published in 2013 by the German National Academy of Science and Engineering. According to Kagermann [2] the "Industrie 4.0 is a new level of value chain organization and management across the lifecycle of products". One of the differentials of the companies are the early launch of the products and the ability to the develop them, with the objectives to meet the growing needs and expectations of the customers. The product lifecycle is getting shorter, which encourages the continued flow of new product development projects in the industry. Increasing competition is forcing companies to enhance their information systems, decision-making techniques, and processes. One of the opportunities is to seek help from Product Lifecycle Management (PLM). As defined by Stark, 'PLM is the business activity of managing, in the most effective way, a company's products all the way across their lifecycles; from the very first idea for a product all the way through until it's retired and disposed of [3]. In this emerging scenario of Industry 4.0 there is an interest in evaluating the PLM domain under the influence of this new industrial revolution. In this scenario, the review of present maturity models in PLM represents a promising opportunity in this investigation. So, a research question then arises: How is the relation between the Product Lifecycle Management Maturity Models and the Industry 4.0?

In the remaining part of this paper, a literature review based on the ProKnow-C method is presented, in order to identify Product Lifecycle Management Maturity Models and their main concerns and assessment criteria. The Product Lifecycle Management Maturity Models are presented in Section 3 following by the concepts of RAMI 4.0 in section 4 . Section 5 is devoted to discuss the results from the conceptual adherence analysis of PLM Maturity Models to the Industry 4.0 perspectives. At the end, the conclusion and future work is given in Section 6.

\section{Research Methodology}

The first phase of the work consisted in the implementation of a well-defined method to structure the systematic review. Review of the literature precedes the development of a research project and aims to highlight the already widespread scientific knowledge on the subject. The literature review allows to the researcher: 1) consolidate the knowledge about the subject that you want to investigate; 2 ) evaluate the scientific relevant and the uniqueness of the proposed work; 3 ) establish the scientific basis used to highlight the frontier of the knowledge on the topic; 4) evaluate the worldview adopted, the potential and opportunities to contribute to the subject. In order to accomplish this research, the structured process Knowledge Development Process Constructivist (ProKnow-C) was chosen [4]. The process ProKnow-C is composed of four macro stages: (1) to select a bibliographic portfolio on the theme, (2) to conduct a bibliometric analysis of the articles of the selected bibliographic portfolio and its references in order to identify the main periodicals, authors, articles and keywords, (3) to perform a systemic analysis of the articles of the selected biblio- 
graphic portfolio, based on the theoretical views of performance evaluation, (4) to identify the gaps in the literature and suggest opportunities for future research.

According to the references, it is necessary to define the main question around to the systematic review. The main question addressed in this paper is: What are the main maturity models in Product Lifecycle Management? The research question was essential for the survey keywords definition as well as for the papers evaluation. The initial keywords were defined for the two axes of research previously described: (i) Axis 1 - Product Lifecycle Management. (ii) Axis 2 - Maturity. The parameters for identifying the articles are essential in order to answer the research questions and to reduce the likelihood of bias. These criteria made it possible to include or exclude case studies emerging from the research databases.

The criteria used in the selection of the database is that should be in the CAPES (Coordination of Improvement of Higher Education Personal) portal. This portal provides search tools that are compatible with Boolean expressions, as well as tools that allow the search of the title, abstract and keyword fields. To obtain a comprehensive set of papers, the search string was constructed through the combination of the operator 'and', were published in journals, conference proceedings book series, and were written in the English language. The survey was carried out through the following search engines: Science Direct, Springer, IEEE, SCOUPS and Web of Science, accessed by the Pontifical Catholic University of Parana.

The alignments of the keywords in the database were verified through the amount of papers for the combination of the keywords. The selection of the database occurred from the verification of the basis that allows entire access through the CAPES portal. As the results of this first research, 262 publications, conference proceedings and book series were found. In the phase of filtering the batch of rough articles, the 262 publications of the batch of rough articles were evaluated according to the following aspects: (i) if the articles are not repeated (redundancy); (ii) if the titles of the articles are aligned with the theme of the research; if the articles possess scientific knowledge; (iii) if the abstracts of the articles are aligned with the theme of the research; (iv) if the entire text of the article is aligned with the theme of the research. As a result, 41 repeated papers were excluded and 221 original papers remained.

In the analysis of the alignment of the title with the theme of the research, it was noticed that some of the selected papers focused on the areas of construction industry, medicine and enterprise communication, and were thus beyond the focus of the research, so 113 papers were removed. A total of 108 original papers, the titles of which were aligned with the theme of the research, were retained. It must be pointed out that the removed articles did not present total alignment with the theme of the research and were nonetheless kept for more detailed analysis in the following phases.

The next phase consisted of the verification of scientific recognition of the papers; in this phase 22 papers were removed. The next step consisted of reading the 86 abstracts of the papers, aiming to verify the alignment of the article with the theme of the research, so 49 were removed. Finalizing the step of filtering the batch of rough articles, the 37 selected papers were analyzed according to the availability and alignment of the whole text with the theme of the research. It's important to describe that this research didn't have only the objective to identifying the main maturity models, 
but also the perspectives and criterias involved in the analysis and dimension of Industry 4.0 .

\section{Product Lifecycle Management Maturity Models}

In this section, the 37 selected papers were analyzed having the objective of identifying the Product Lifecycle Management Maturity Models. The Product lifecycle management (PLM) is the process of managing the entire lifecycle of a product from its first concept, through design and manufacture, to service and disposal. PLM integrates people, data, processes and business systems and provides a product information backbone for companies and their extended enterprises [5].

According to [6], basic elements of all maturity models are number of dimensions (such as the 'process areas' in Classification of Maturity Models (CMM's)), number of levels (typically three to six), and a descriptor for each level (such as the CMM's differentiation between initial, repeatable, defined, managed, and optimizing processes). Maturity can be defined as "the state of being complete, perfect or ready" [7]. The main Product Lifecycle Management Maturity Models extracted from the systematic literature review are described below:

Batenburg Proposal: is designed to assess the PLM achievements of individual companies or business units of a company [8]. Applies four maturity levels: (1) ad hoc (where there is no vision available for PLM and there are no consistent PLM processes and supporting systems), (2) departmental (where PLM is seen as data management problem that should be dealt with on departmental level that starts to implement PLM systems), (3) organizational (where PLM is interpreted as a business problem that requires a corporate vision and an integral approach and PLM systems are integrated with other major enterprise systems, such as ERP) and (4) interorganizational (where PLM is seen as a business problem that spans the complete product lifecycle and PLM systems are integrated with those of the suppliers to enable collaboration).

Saaksvuori and Immonen proposal: Identifies five stages: (1) unstructured (where there are no defined approaches concerning lifecycle management; all lifecycle and product management issues are resolved by individuals on a case-by-case basis), (2) repeatable but intuitive (where lifecycle and product management processes have left to individuals, there is not any formal development, definition, training or communication of standard processes), (3) defined (where the PLM processes or basic PLM concepts are not best-of-the-breed, nor are they uniform throughout the corporation, however they are formalized), (4) managed and measurable (where PLM processes and concepts are under constant improvement and provide best practices) and (5) optimal (PLM processes and concepts have been refined to the level of best practice, based on continuous improvement and benchmarking with other organizations).

Schuh et al.: have implemented a framework that comprehends seven maturity elements of PLM: (1) the PLM definition (that provides the boundaries within which the reference models are detailed), (2) the PLM foundation (based on the specification of the fundamental concepts for the PLM implementation), (3) the set of process ref- 
erence models (that vary according to a group of features of a company, sector, size, order type, which coherently define typical industrial enterprises), (4) the vendor neutral software description (that lists the software requirements needed to support process activities), (5) the PLM software support (that identify the profiles of specific Software solutions), (6) the knowledge base (that supplies the necessary material to support training), (7) the PLM benefits (like reducing time-to-market, improving product functionality and increasing ability of customizing resulting from changes within the company's processes after PLM implementation).

Stark Proposal: defined a maturity model for PDM, which is an important component of PLM. The model is composed of six maturity stages: (1) Traditional, (2) Archipelago of PLM Islands, (3) Frontier-crossing PLM, (4) Enterprise-wide, (5) Enterprise-wide, (6) Enterprise-deep. For each of these stages he described particular features from three different viewpoints: the company, the product development process and PDM. He also developed a questionnaire based on this model on basis of which a company can be assessed with respect to PDM maturity. The assessment is used to determine the current situation of a company.

Kärkkäinen et al. Proposal: examined how organizational maturity should be assessed in order to successfully implement and develop a PLM scheme. They define the maturity of customer dimension, and they provide preliminary maturity level descriptions for this dimension. In the level descriptions of maturity in customer dimension, they discern the following main levels, namely (1) Chaotic, (2) Conscientious, (3) Managed, (4) Advanced and (5) Integration stages.

Terzi S.: defines a model of assessment for the new product development process that provides a snapshot of the company in order to offer a starting point for further analysis and the definition of a strategy for improvement in its processes of engineering and innovation [9]. The proposed model identifies three aspects of investigation: Organization, Process and Knowledge Management, divided into nine subareas totals. The model elaborates the five levels of maturity usually defined in the literature, identified by the acronym Climb: (1) Chaos, (2) Low, (3) Intermediate, (4) Mature, (5) Best Practice.

\section{RAMI 4.0}

To provide a common base around the Industry 4.0, a group of collaborators from different European enterprises and R\&D institutions suggested a "reference architectural model" for Industry 4.0 (RAMI 4.0, figure 01), which purpose is the grouping and representation of different aspects of the industry in a common model, vertical integration, end-to-end engineering and horizontal integration [10]. The horizontal integration refers to the integration of the various IT systems used in the different stages of the manufacturing and business planning processes that involve an exchange of materials, energy and information both within a company. The vertical integration refers to the integration of the various IT systems at the different hierarchical levels. In general, the RAMI 4.0 provides "basic reference architecture" for an Industry 4.0 [10]. The architecture model requires a three-dimensional representation. The three axes of RAMI 4.0 describe the hierarchical levels of a manufacturing system net- 
worked via the Internet, the lifecycle of systems and products, and the IT structure of an Industrie 4.0 component.

The description of the lifecycle of systems and products with the corresponding value-added chains is based on the draft of IEC 62890, which makes a distinction between type and instance. The type of a product appears in several phases during the development process. Based on the type released for series production, the system then manufactures products that are instances of the type. Component discontinuations or improvements may require changes to products. These changes are made to the type and are introduced into the manufacturing process as a new product version once the change has been finalized and released. The data generated in the process chains is already largely available in digital form. It is then processed in PLM and ERP systems. In order to manufacture individual products, it must be possible to store the data provided by customers to producers for the manufacture of their instances electronically in a suitable, instance-related format in IT systems. This data must be available throughout the entire lifecycle of the instance and linked to the associated type.

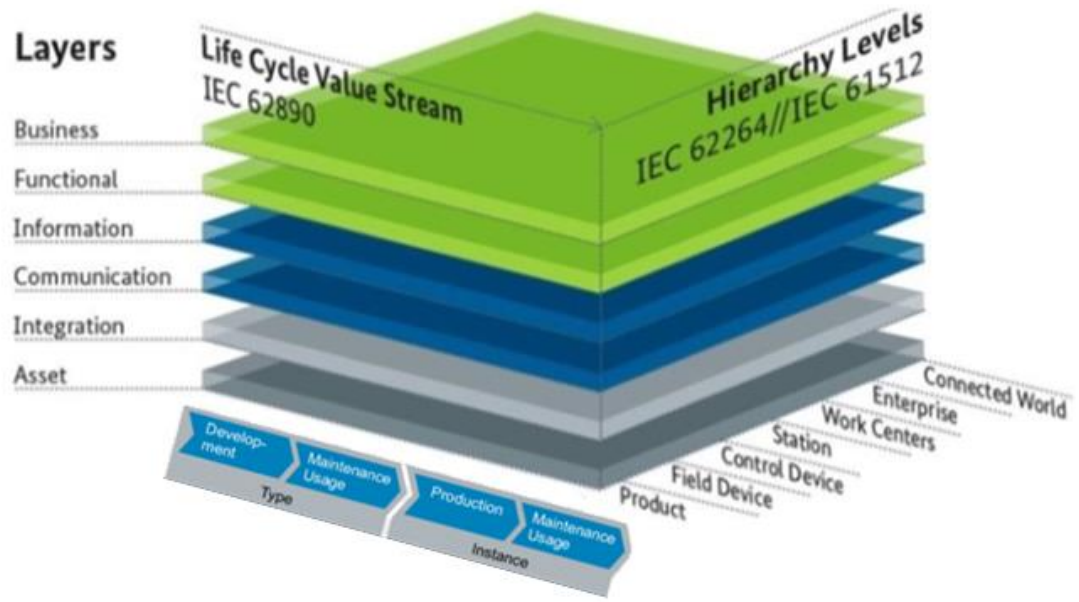

Fig. 1. Overview RAMI 4.0 (Plattform Industrie 4.0 e ZVEI, 2015).

Hierarchy Levels: a horizontal axis that is based on the IEC 62264, an international standard for enterprise control system integration, that presents four layers called 'Enterprise', 'Work Centers', 'Station', and 'Control Device' (from top to bottom). In the RAMI 4.0 were added three layers to support the smart factory. At the bottom are the 'Field Device' (to enable the control of machines or systems in an intelligent way, e.g., smart sensors) and 'Product or Workpieces'. At top was added the 'Connected World' layer, whereby the factory can go beyond its boundaries and reach external partners by collaborative service networks. These layers represent the fundamental aspects for the Industry 4.0 organization.

Life Cycle and Value Stream: this axis describes assets in the value stream from idea, development and maintenance with respect to an asset type and the production, usage and maintenance of the concrete instances of the asset type, which is based on IEC 62890, a draft standard for guideline life cycle management. 
Layers: a vertical axis to describe the decomposition of machines and physical entities in a way to enable its virtual mapping. The layers are used to represent perspectives, such as data maps, functional descriptions, communications behavior, hardware/ assets or business processes, they define a structure of ICT representing the Industry 4.0. The corresponding layers of this axis from top to bottom are 'Business', 'Functional', 'Information', 'Communication', 'Integration', and 'Asset'.

\section{$5 \quad$ Relational analysis approach}

In the next subsections, are devoted to discuss the results from the conceptual adherence analysis of PLM Maturity Models to the Industry 4.0 perspectives.

In order to get an overview about the maturity models in PLM domain, the research grouped the attributes into five aggregated categories, following the structure proposed in [11] and shown in table 1. In the category of Detail Level are describe the "Business Dimensions" and "Maturity levels". The aggregate category named Testing groups attributes such as "Number of questions" and "Total number of respondents". Effectiveness groups attributes such as "Practicality of evidence" and "Guidelines for the PLM implementation". The category named Application groups attributes such as "Support of application", "Method of application" and "Mutability. The last category, Addressed Domain groups the attribute "Concept of maturity". The weights of this table were used as a reference to do the pair-wise comparison in the AHP method.

Table 1. PLM Maturity Models.

\begin{tabular}{|c|c|c|c|c|c|c|}
\hline $\begin{array}{c}\text { Maturity } \\
\text { Models }\end{array}$ & Batenburg & Schuh & Saaksvuori & Stark & Kärkkäinen & Terzi \\
\hline Detail Level & 1.72 & 1.11 & 1.51 & 1.75 & 3.33 & 2.29 \\
\hline Testing & 1.87 & 0.00 & 0.00 & 0.00 & 0.00 & 2.00 \\
\hline Effectiveness & 1.00 & 0.50 & 1.50 & 1.00 & 0.50 & 0.50 \\
\hline Application & 2.33 & 1.17 & 1.17 & 1.17 & 1.17 & 1.67 \\
\hline $\begin{array}{c}\text { Addressed } \\
\text { Domain }\end{array}$ & 0.75 & 0.75 & 0.75 & 0.75 & 1.00 & 1.00 \\
\hline Total Score & 7.67 & 3.53 & 4.93 & 4.67 & 6.00 & 7.46 \\
\hline
\end{tabular}

The second analyze (table 2), describe the relation between the Rami 4.0 axes with the PLM maturity models. The signals $(+),(++),(+++)$ are used to weight a weak, medium and strong relationship between the concepts, respectively. In the axis described as Layers, the "Assets" are the physical elements (sensors, actuators) that make up the real world and provide timely information on particular equipment. The Batenburg and Kärkkäinen has the biggest relationship because has the part of Control well defined in their process. The level of "Integration" is the form that this data will be transmitted from the real world to the digital world, that is, they are protocols and communication interfaces (OPC-UA, etc.). In this level all the PLM maturity models has the structured data. The "Communication" layer is where the information will be available to be accessed the way it is collected in the physical environment. The Schuh model has the knowledge base as a strong characteristic and receives the highest weighting in the table. The "Information" layer is the structuring of the ac- 
quired data that allows it to become clear to the users. In this layer, the Stark Model has a fragile relanthioship, because the main objective is the product data management. The "Functional" level holds the set of elements that make up the assets functions, allowing the entire factory floor to be integrated and its shared information guaranteeing the complete integration of the process. In this layer the highest values were weighted to the Batenburg and Kärkkäinen models, because both models working with real information from the factory floor. And finally, the "Business" layer, which evaluates all the data generated so that important decisions are made to improve production where several business areas are directly involved. The concepts of Batenburg, Schuh and Kärkkäinen are the models that best working with data to support a decision making. To the axis Life Cycle Value Stream all the requirements has a strong relationship, because all the Maturity Models has the product phase information as an application. In the axis Hierarchy Levels, the layer "Product" has a strong relation with all the PLM maturity models. The layer "Field Device" consists of standard terminology and object models that are used to define which information to exchange. In this case, the Saaksvuori model has the best performance, because has a good reference guideline for implementation. The third layer "Control Device" consists of attributes for each objective defined in layer 02. Objects and attributes can be used to provide and exchange information between different systems, but can also be composed as a relational database base. As in the second layer, the Saaksvuori model still has the best relation. The fourth level "Station" concentrates on the functions and activities of the production layer. It provides guidelines for describing and comparing the production levels of different websites in a standardized way. The Batenburg, Schuh, Saaksvuori and Kärkkäinen models are the reference to compare data of the production. The fifth level "Work Centers" the technical specification defines object models that determine what information is exchanged between the MES activities. The models and attributes are the basis for the design and implementation of interface standards that ensure the flexibility and exchange of information between different requests. All models have in evidence these characteristics, with the exception of the Stark and Terzi models paying less attention to these concerns. The layer "Enterprise", operations connects and organizes production and activities through the definitions from previous levels. The main models followed the reference of the last layer. "Connected World" has external platforms that are capturing data from your internal processes. One of the most traditional technologies is Cloud Computing. The Batenburg and Kärkkäinen model has the Information technology as an important characteristic.

Table 2. PLM Maturity Models x RAMI 4.0.

\begin{tabular}{|c|c|c|c|c|c|c|}
\hline & Batenburg & Schuh & Saaksvuori & Stark & Kärkkäinen & Terzi \\
\hline Layers & Axis 1 & Axis 1 & Axis 1 & Axis 1 & Axis 1 & Axis 1 \\
\hline Business & ++ & ++ & + & - & ++ & - \\
\hline Functional & +++ & + & ++ & - & +++ & - \\
\hline Information & ++ & + & + & - & + & ++ \\
\hline Communication & - & +++ & - & + & - & + \\
\hline Integration & + & + & + & + & + & + \\
\hline Asset & +++ & - & - & + & +++ & + \\
\hline
\end{tabular}




\begin{tabular}{|c|c|c|c|c|c|c|}
\hline Life Cycle Value Stream & Axis 2 & Axis 2 & Axis 2 & Axis 2 & Axis 2 & Axis 2 \\
\hline Development & +++ & +++ & +++ & +++ & +++ & +++ \\
\hline Maintenance Usage (Type) & +++ & +++ & +++ & +++ & +++ & +++ \\
\hline Production & +++ & +++ & +++ & +++ & +++ & +++ \\
\hline $\begin{array}{c}\text { Maintenance Usage (In- } \\
\text { stance) }\end{array}$ & +++ & +++ & +++ & +++ & +++ & +++ \\
\hline Hierarchy Levels & Axis 3 & Axis 3 & Axis 3 & Axis 3 & Axis 3 & Axis 3 \\
\hline Product & +++ & +++ & +++ & +++ & +++ & +++ \\
\hline Field Device & ++ & + & +++ & ++ & + & ++ \\
\hline Control Device & ++ & + & +++ & ++ & + & ++ \\
\hline Station & ++ & - & ++ & - & ++ & ++ \\
\hline Work Centers & +++ & +++ & +++ & - & +++ & - \\
\hline Enterprise & ++ & ++ & ++ & - & ++ & - \\
\hline Connected World & + & - & - & - & + & - \\
\hline
\end{tabular}

In order to prioritize the selection criteria, and to distinguish in general the more important criteria from the less important ones, further investigation was conducted by employing the AHP approach [12]. The AHP method helped to specify numerical weights representing the relative importance of each individual criteria (Maturity Models, Layers, Life Cycle Value Stream and Hierarchy Levels) as well as their associated selection criteria with respect to the goal. In the level 1 is showed the selection of the criteria. Level 2 is realized the analyze of the categories, with concepts of PLM Maturity Models and Industry 4.0, that has the RAMI 4.0 with a reference. In the next level, is realized the analyze of the attributes, that have criterias with concepts from the literature of PLM Maturity Models and I 4.0 (Rami 4.0) The last level, is demonstrated the alternatives. The pair-wise comparison judgments were made with respect to the attributes of one level of hierarchy given the attribute of the next higher level of hierarchy (from the main criteria to the sub-criteria). For designing the paired comparison matrices, the decision hierarchies were formed as visualized in figure 02 .

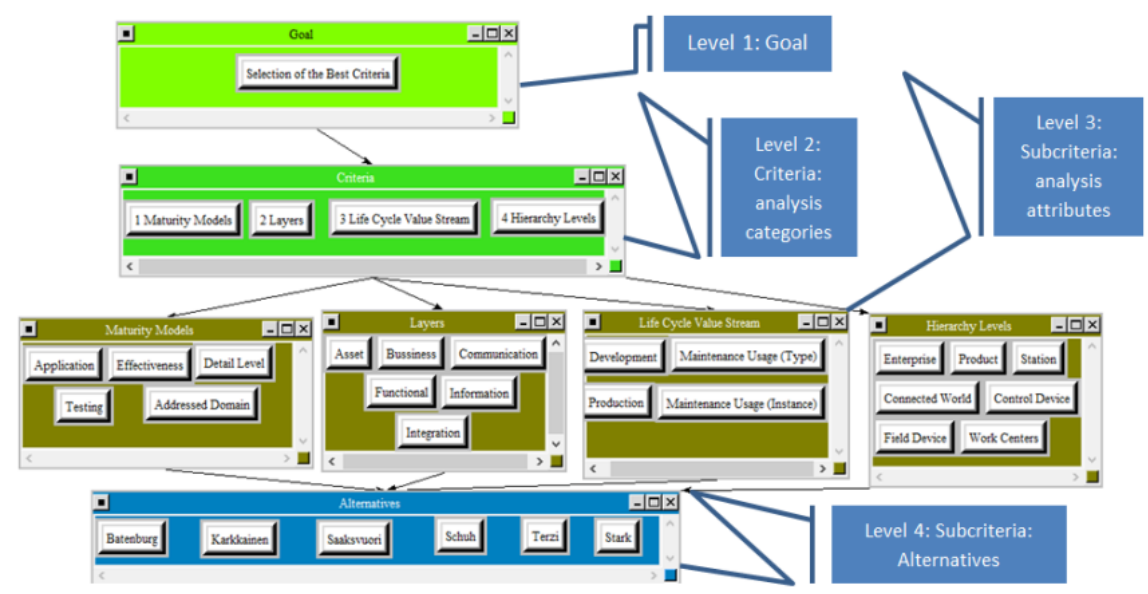

Fig. 2. The decision hierarchy for selecting PLM Maturity Models. 
Figure 03 shows the final result of the AHP analysis comparing the axis Maturity Models, Layers, Life Cycle Value Stream, Hierarchy Levels and following the weighting of the table 1 and table 2 . Is evidenced that the Batenburg maturity model had the highest score $(18,83 \%)$ between the models. The Kärkkäinen model $(17,71 \%)$ is the second that presented the greatest score, followed by the Terzi model $(17,47 \%)$.

\begin{tabular}{|l|l|l|l|l|}
\hline \multicolumn{1}{|c|}{ Name } & Graphic & Ideals & Normals & Raw \\
\hline \hline Batenburg & & 1.000000 & 0.188394 & 0.062798 \\
\hline \hline Karkkainen & & 0.940359 & 0.177158 & 0.059053 \\
\hline \hline Saaksvuori & & 0.878351 & 0.165476 & 0.055159 \\
\hline \hline Schuh & & 0.826439 & 0.155697 & 0.051899 \\
\hline \hline Stark & & 0.735120 & 0.138493 & 0.046164 \\
\hline \hline Terzi & & 0.927743 & 0.174782 & 0.058261 \\
\hline
\end{tabular}

Fig. 3. Analysis of Result.

From AHP method a sensitive analysis was conducted in order to determine the stability of the outcome to wide perturbations in the judgments. In figure 04 , it is represented, for instance, the Asset node (attribute) with a 0,80 weighting factor. In this parameter, represented on the y-axis (percent) the Batenburg method still have the highest weight $(19,1 \%)$ but now the Terzi method has the second weight $(18,3 \%)$. Each one attributes relating in each category (criteria and Subcriteria) are objects of the sensitivity analysis, allowing a refined research on the adherence of PLM MMs on the scope of evaluation in Industry 4.0 domain.

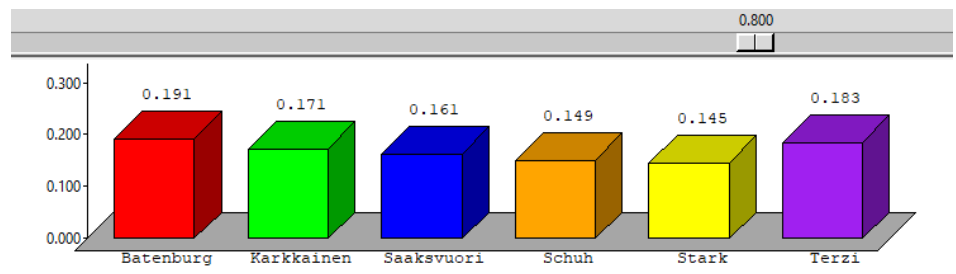

Fig. 4. PLM comparative models - Asset node.

\section{Conclusions}

In a first step, a literature review was conducted founded on the methodology Knowledge Development Process Constructivist (ProKnow-C), in order to identify the main Product Lifecycle Management maturity models. As a result, six relevant PLM maturity models were identified.

In a second step, an investigation on how the relation between the PLM maturity models and Industry 4.0 is characterized. For this research the RAMI 4.0 (Reference Architectural Model Industrie 4.0) was adopted as a reference, because combines all IT elements of Industry 4.0 in a layer with a product lifecycle model. Through an AHP analysis, a comparison (weighting) on the maturity models characteristics with 
the layers of the RAMI 4.0 was carried out. In the research, it was identified that the PLM maturity model with greater adherence to industry 4.0 dimensions was the Batenburg maturity model highlighting highest final score.

It's fact that the Industry 4.0 concepts involve the integration of the physical and digital technologies with the phases of the Product. When this integration happens in the right way, many opportunities are found: the company can allocates efficiently the machines, identify problems quickly, reduce the production bottleneck, optimize process, reduce defects in products and prevent problems before manufacturing the prototype. The integration between these areas provides more customization to the production and to the product, reducing the product development time and the time required to market the finished product.

\section{References}

1. Kagermann, Henning, Wolfgang Wahlster, and Johannes Helbig. Recommendations for Implementing the Strategic Initiative INDUSTRIE 4.0. Berlin: Industrie 4.0 Working Group of Acatech, (2013).

2. Kagermann et. Al. Industrie 4.0 Mit dem Internet der Dinge auf dem Industrially Revolution, (2011).

3. J, Stark. Opportunities and PLM, Product Lifecycle Management: Paradigm for 21St Century Product Realization, Springer-Verlag, London, UK: pp. 81-92. (2011). doi: 10.1007/978-0-85729-546-0

4. F, Rosa. S, Rolim. R, Ensslin. "Environmental disclosure management: a constructivist case", Management Decision, Vol. 50. 2, pp. 47-62. (2013). doi: 10.1590/010337862015000300004

5. Saaksvuori A, Immonen A. Integration of the PLM system with other applications. Product Lifecycle Management: Springer-Verlag Berlin Heidelberg: pp. 53-65. (2008). doi: $10.1007 / \mathrm{b} 138258$

6. Mettler, T. A design science research perspective on maturity models in information systems. Universität St. Gallen, St. Gallen, Switzerland, Technical Report (2009).

7. H. Karkkainen, A. Silventoinen, Different Approaches of the PLM Maturity Concept and Their Use Domains - Analysis of the State of the Art, in: 12th IFIP WG 5.1 Int. Conf. PLM 2015, Springer International Publishing Switzerland, Doha, Quatar, 2015: pp. 89102. (2016). doi: 10.1007/978-3-319-33111-9_9

8. Batenburg, R., \& Versendaal, J. Maturity matters: Performance determinants of the procurement business function. Paper presented at the Proceeding at the16th European Conference on Information Systems. Galway, Ireland (2008).

9. Frigerio G, Rossi M, \& Terzi S SVILUPPO NUOVO PRODOTTO-Benchmarking dei processi di Sviluppo Prodotto. Sistemi e Impresa (3), 40, (2012). doi: 10.1007/s00170-0135529-1

10. Platform Industrie 4.0. Referencial Architectural Model Industrie 4.0 (RAMI 4.0), (2016).

11. Enrico Vezzetti \& Maria Grazia Violante \& Federica Marcolin A benchmarking framework for product lifecycle management (PLM) maturity models, Springer-Verlag, London, Int. J. Adv. Manuf Technol. UK: pp.899-918. (2013). doi: 10.1007/s00170-013-5529-1

12. Al-Harbi K Al-S application of the AHP in project management. International Journal of Project Management: pp. 19-27 (2001). doi: 10.1016/S0263-7863(99)00038-1 